\title{
An inexpensive reinforcement dispenser
}

\author{
CHARLES W. HYATT \\ The Union Institute, Cincinnati, Ohio \\ and Yerkes Regional Primate Research Center. \\ Emory University, Atlanta, Georgia \\ and \\ DAVID A. LEAVENS \\ University of Georgia, Athens, Georgia \\ and Yerkes Regional Primate Research Center \\ Emory University, Atlanta, Georgia
}

An inexpensive (less than \$35) solid food reinforcement dispenser was developed using commercially available parts for commonly found vending machines. This device proved to be reliable and efficient in repeated use with laboratory primates in a video task testing situation.

Increasing costs of laboratory equipment can seriously limit scientists' ability to conduct behavioral research. Although universal dispensers can provide economical distribution of small solid food items, costs of commercially available products can be prohibitive. Gerbrands model 70 , for example, currently lists for $\$ 1,210$. In an effort to reduce costs and to increase the size and variety of items that can be dispensed, a simple and inexpensive food dispenser was developed utilizing a motor and spiral delivery system for small solid food items (.1-5 g and/or about $1-10 \mathrm{cc}$ ) in widely found vending machines. This apparatus provided delivery of consumable reinforcers as efficiently as far more expensive systems.

The need for lower cost reinforcement dispensers has been recognized in the past by Fobes, King, and Davison (1974), and by Heth (1979), who developed inexpensive feeders suitable for use in psychological laboratory research. Fobes et al. used parts from a typewriter then costing less than $\$ 20$; Heth used a simple plastic, latch, and magnet design that "can be constructed in a modest carpentry shop" (p. 45). Takahashi (1995) developed a universal feeder for under $\$ 200$ that could dispense up to 64 solid food items of irregular sizes. We sought to develop an even simpler and less expensive apparatus that could be interfaced with microcomputers and automated psychological testing systems, such as the video task software developed by Richardson, Washburn, Hopkins, Savage-

Portions of this research were supported by Grant NS-29574 to W. D. Hopkins and a grant from the National Center for Research Resources RR-00165 to the Yerkes Regional Primate Research Center. D.A.L. gratefully acknowledges the support of a Morris Doctoral Fellowship, Graduate School, Southern Illinois University, Carbondale. Thanks to P. Bryan and A. Brodie for the figure illustration. The Yerkes Regional Primate Research Center is accredited by the American Association for Accreditation of Laboratory Animal Care. The APA standards for the ethical treatment of animals were adhered to during all aspects of this study. Correspondence should be addressed to C. W. Hyatt, Yerkes Regional Primate Research Center, Emory University, Atlanta, GA 30322.
Rumbaugh, and Rumbaugh (1990). This software package facilitates the responding by primates to computergenerated stimuli via the manipulation of a joystick. It then builds to more complex automated tasks such as options for maze running, discrimination learning set, and matching-to-sample tests, among others.

An auger spiral motor (Part No. 360138) and three miscellaneous spirals $(15,24$, and 30 count $)$ were obtained from Automated Products of St. Paul, MN, through Greater Southern Distributing of Atlanta, GA, for approximately $\$ 21$. These items are commercially available as parts for commonly found snack-food vending machines, and they are built to provide numerous and repeated delivery of solid food items such as candy, chips, and gum. The delivery system operated by sending an electric signal from the selection pad to a small motor, which then turned a spiral coil, moving the desired item forward and off the end of its rack. We mounted this simple motor and spiral combination to wooden blocks placed on the plastic housing of our testing computer's mobile cart. The spiral coil rested in a $7.5-\mathrm{cm}$ diameter polyvinyl chloride (PVC) tube, $60 \mathrm{~cm}$ long and halved longitudinally, which sat on the top of the housing. A second PVC tube was diagonally mounted on the side of the housing for receipt of food items from the spiral above. A Keithley MetraByte DASCON-1 Electromechanical Relay Board mediated a 24-V dc current from an IBM personal computer to the motor and spiral. On the relay board, the signal was relegated to relay $\mathrm{K} 1$ via the "normally open" (NO) and "center" (C) terminals of PB0. The first switch (S1) was set to "internal power." Positive and negative leads could be alternated to reverse the turning direction of the motor and spiral, Two of these apparatuses were developed (Figure 1).

Four chimpanzees (Pan troglodytes), 1 male and 3 females, 14-44 months of age, were tested on these apparatuses. The 4 subjects were trained on the "side" and "chase" components of the Richardson et al. (1990) computer tasks. 


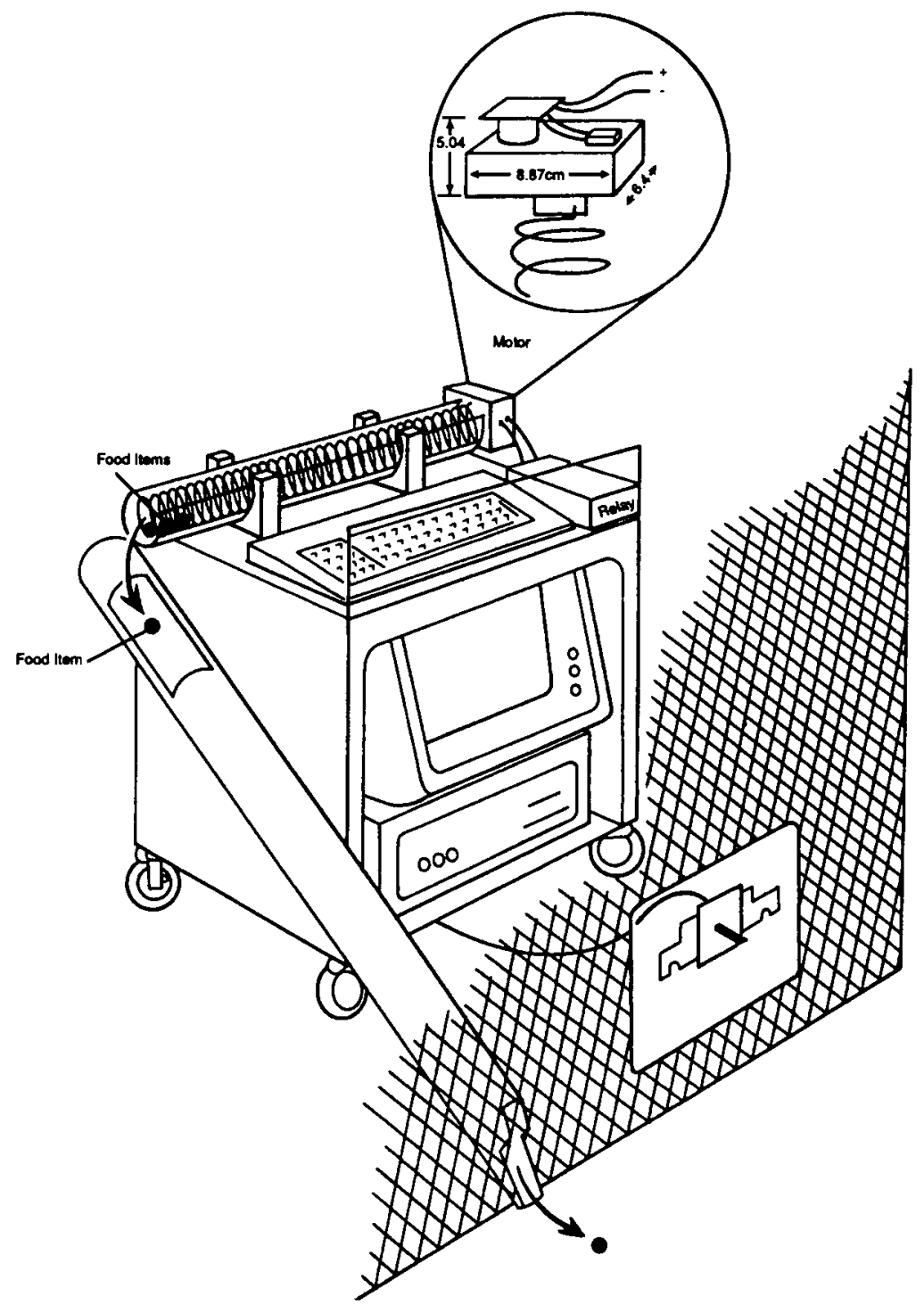

Figure 1. Apparatus: Auger motor, 30-count spiral, PVC tubing, and relay board mounted on computer housing unit.

In these tasks, subjects had to manipulate the joystick placed through the wire mesh of their cage to control the movement of a cursor on their monitor screen. The cursor was to be moved to a lit portion of the screen, either one to four sides of the screen in "side" or a moving target in "chase." Upon the receipt of a "correct" signal from the PC via the relay board, the apparatus motor turned the spiral one complete revolution (lasting about $2.2 \mathrm{sec}$ ), and a peanut or grape was sent off the end of the first tube, into the second, and down into the animals' cages. Subjects typically performed 50-200 trials per day over a 2-month period. Over 2,500 trials were completed for each of the subjects with successful dispensation of reinforcement from this type of apparatus. There were no apparatus failures noted.

This dispenser device was inexpensive to obtain and simple to construct. Although it holds fewer items than commercially available universal dispensers ( 30 items vs. about 70 ), it has the potential to be as reliable and efficient as far more expensive models in use by laboratories.

\section{REFERENCES}

Fobes, J. L., KING, J. E., \& Davison, C. H. (1974). An inexpensive universal feeder. Behavior Research Methods \& Instrumentation, 6, 69 HETH, C. D. (1979). An inexpensive universal feeder suitable for small numbers of large rations. Behavior Research Methods \& Instrumentation, 11, 45-46.

Richardson, W. K., Washburn, D. A., Hopkins, W. D., SavageRumbaugh, E. S., \& Rumbaugh, D. M. (1990). The NASA/LRC computerized test system. Behavior Research Methods, Instruments, \& Computers, 22, 127-131.

TAKAHASHI, M. (1995). A low-cost universal feeder. Behavior Research Methods, Instruments, \& Computers, 27, 73-75.

(Manuscript received February 7, 1995; revision accepted for publication January 22,1996 .) 